\title{
PEMBELAJARAN MATEMATIKA MELALUI MEDIA GAME QUIZIZZ UNTUK MENINGKATKAN HASIL BELAJAR MATEMATIKA SMP 2 BOJONEGARA
}

\section{(MATHEMATICS LEARNING WITH QUIZIZZ GAME MEDIA TO IMPROVE MATHEMATICS LEARNING OUTCOMES OF SMP 2 BOJONEGARA)}

\author{
Sri Mulyati ${ }^{1}$, Haniv Evendi ${ }^{2}$ \\ ${ }^{1}$ SMPN 2 Bojonegara, sri.mulyati.spd@gmail.com \\ ${ }^{2}$ SMP Muhammadiyah Kragilan, hanifevendi97@gmail.com
}

\begin{abstract}
Abstrak
Kemajuan ilmu pengetahuan serta teknologi informasi dan komunikasi sebagai salah satu produk perubahan zaman banyak membawa dampak positif bagi kemajuan dunia pendidikan sekarang ini. Era digitalisasi yang disebut era revolusi industri 4.0 membuat perubahan yang sangat cepat. Banyak aplikasi pembelajaran digital yang bisa digunakan secara efektif dan efisien sebagai media penunjang pembelajaran, Penelitian ini membutuhkan inovasi media pembelajaran agar siswa tidak merasa bosan pada saat proses belajar mengajar. Banyak aplikasi pembelajaran digital yang bisa digunakan secara efektif dan efisien sebagai media penunjang pembelajaran Tujuan penelitian ini yaitu : mengetahui peningkatan hasil belajar siswa pada materi teorema Pythagoras kelas VIIIA di SMPN 2 Bojonegara. Jenis penelitian ini adalah Penelitian Tindakan Kelas (PTK). Pengumpulan data dengan menggunakan metode tes dan observasi bulan Januari - Februari 2020. Hasil penelitian ini yaitu; terdapat peningkatan hasil belajar rata - rata hasil belajar pada siklus I sebesar $63 \%$ dan siklus II sebesar $78 \%$.
\end{abstract}

Kata kunci: Game Quizizz, Hasil Belajar Matematika

\begin{abstract}
The advancement of science and information and communication technology as one of the products of changing times has had a positive impact on the progress of today's education world. The era of digitalization called the era of the industrial revolution 4.0 made changes very quickly. Many digital learning applications can be used effectively and efficiently as learning support media. This research requires learning media innovation so that students do not feel bored during the teaching and learning process. Many digital learning applications that can be used effectively and efficiently as learning support media The purpose of this research is: to find out the increase in student learning outcomes in the VIIIath Pythagorean theorem material at SMPN 2 Bojonegara. This type of research is Classroom Action Research (CAR). Data collection using the test and observation methods from January to February 2020. The results of this study are; there is an
\end{abstract}


increase in learning outcomes on average learning outcomes 63 in cycle I and 78 in cycle II.

Keywords: Quizizz Game, Mathematics Learning Outcomes

\section{PENDAHULUAN}

Kemajuan ilmu pengetahuan, teknologi informasi dan komunikasi yang demikian cepat diharapkan membawa dampak positif bagi kemajuan dunia pendidikan sekarang ini. Era digitalisasi yang sekarang lebih tren disebut era revolusi industri 4.0 , telah merambah ke berbagai sektor temasuk pendidikan. Hal ini dapat menjadi media yang sangat efektif dan efisien untuk digunakan sebagai penunjang proses pembelajaran. Beragam fasilitas multimedia berbasis IT dapat dimanfaatkan agar proses pembelajaran menjadi lebih menarik. Berbagai aplikasi pembelajaran menarik baik gratis maupun berbayar sudah tersedia untuk bisa dimanfaatkan maksimal bagi generasi milenial. Penggunaan teknologi informasi di zaman globalisasi dan era digital ini tidak dapat dikesampingkan dan menjadi suatu kebutuhan yang sangat vital oleh masyarakat, sehingga perkembangan teknologi informasi sangat berkembang pesat dan maju serta mendapat minat yang sangat baik oleh masyarakat. Perkembangan teknologi informasi yang ini sangat berpengaruh dalam berbagai kehidupan Salah satunya berdampak positif dalam bidang pendidikan (Basori, 2013; Herlambang \& Hidayat, 2016) yang mengakibatkan mutu pendidikan meningkat (Nasrullah, Ende, \& Suryadi, 2017). Penggunaan smartphone dan internet yang seimbang dan dimanfaatkan dengan baik khusunya pada dunia pendidikan, hal ini akan membawa bidang pendidikan untuk maju dan berkembang seiring dengan perkembangannya teknologi informasi dan komunikasi. Maka dari itu proses pembelajaran di sekolah tidak terlepas dari peran teknologi informasi. Misal kegiatan guru dan siswa yang banyak kegiatannya menggunakan media komputer dan internet di sekolah (Maghfiroh, Kirom, \& Munif, 2018).

Matematika merupakan mata pelajaran yang wajib diberikan untuk semua peserta didik atau siswa mulai dari sekolah dasar sampai ke jenjang pendidikan berikutnya. Hal ini agar siswa dapat berpikir secara logis, analitis, sistematis, dan kritis. Mata pelajaran matematika secara umum dipandang oleh siswa sebagai mata pelajaran yang sulit.Sampai saat ini masih banyak siswa yang mengalami kesulitan dan merasa takut untuk belajar matematika.Hal ini dikarenakan pembelajaran yang monoton ataupun karena tidak begitu menyenangkannya belajar matematika.Oleh karena itu, dibutuhkan alternatif pembelajaran yang mampu menjadikan begitu menyenangkannya belajar matematika, salah satunya adalah dengan menggunakan aplikasi yang sudah ada dan sudah disedikan oleh pihak ketiga. Dalam penelitian ini akan dibahas mengenai aplikasi pembelajaran Quizizz yang dapat digunakan oleh guru sebagai alternatif pembelajaran matematika yang menyenangkan. Karena penggunaan model pembelajaran, metode, dan strategi pembelajaran yang tepat dan secara optimal didukung oleh media interaktif telah dikembangkan untuk membangkitkan minat, aktivitas pembelajaran, motivasi, dan hasil belajar siswa dalam proses pembelajaran matematika. Quizizz merupakan sebuah web-tool untuk membuat permainan kuis interaktif yang digunakan dalam pembelajaran di kelas. Kuis interaktif yang 
dibuat memiliki hingga 4 pilihan jawaban termasuk jawaban yang benar dan dapat ditambahkan gambar ke latar belakang pertanyaan. Bila pembuatan kuis sudah jadi, kita dapat membagikan kode ke siswa agar siswa dapat login ke kuis tersebut. Quizizz juga memberikan data dan statistik tentang kinerja siswa. Guru dapat melacak berapa siswa yang menjawab pertanyaan yang telah dibuat, pertanyaan yang harus dijawab dan banyak lagi. Bahkan guru dapat mendownload statistik dalam bentuk Ms. Excel. Quizizz juga memberikan fitur "pekerjaan rumah", sehingga pekerjaan rumah siswa dapat dikerjakan kapan saja dan dari mana saja.Sehingga siswa dapat lebih fleksibel dalam mengerjakan pekerjaan rumah dan guru dapat membatasi waktu pekerjaan rumah tersebut.

Game Quizizz adalah aplikasi pendidikan berbasis game, yang membawa aktivitas multi pemian ke ruang kelas dan membuatnya di kelas latihan interaktif dan menyenangkan (Purba. 2019: 5). Implementasi menggunakan Game Quizizz siswa dapat melakukan latihan di dalam kelas pada perangkat elektronik mereka. Tidak seperti aplikasi pendidikan lainnya, Game Quizizz memiliki karakteristik permainan seperti avatar, tema, meme, dan musik menghibur dalam proses pembelajaran. Quizizz juga memungkinkan siswa untuk saling bersaing dan memotivasi mereka belajar sehingga hasil belajar bisa meningkat. Siswa mengambil kuis pada saat yang sama di kelas dan melihat peringkat langsung mereka di papan peringkat. Instruktur atau guru dapat memantau prosesnya dan mengunduh hasilnya ketika kuis selesai untuk mengevaluasi kinerja siswa. Game Quizizz dapat membantu motivasi belajar siswa dan meningkatkan hasil belajar yang selama ini ujian pakai kertas.

Hal ini menjadi tantangan bagi guru untuk dapat menciptakan pembelajaran yang menarik dan menyenangkan. Pembelajaran yang menyenangkan dapat diciptakan melalui penggunaan berbagai macam model atau metode pembelajaran ataupun dengan menggunakan media pembelajaran yang menarik sehingga dapat membuat siswa menjadi bersemangat untuk belajar dan lebih mudah memahami materi. Pengembangan media pembelajaran menggunakan komputer atau laptop dan handphone atau Smartphone, salah satunya dengan pemanfaatan game edukatif. Game edukatif ini masih jarang ditemui meskipun sudah ada namun pemanfaatan dalam media pembelajaran sangat kurang. Game sebagai media pembelajaran yang diintegrasikan dengan materi atau soal - soal evaluasi diharapkan dapat membuat pembelajaran menjadi lebih menarik dan menyenangkan. Hal ini sependapat dengan Henry (2010: 53 54) yang mengemukakan tentang dampak positif penggunaan game yang salah satunya adalah game menyenangkan dan menghibur serta game memberikan latihan untuk pemecahan masalah dan logika.

Aplikasi kuis online Quizizz dapat digunakan oleh para pengajar untuk melihat sejauhmana siswa dalam belajar. Penggunaan yang mudah dan hasil yang cepat dalam proses penilaiannya menjadikan aplikasi ini layak digunakan sebagai aplikasi pembelajaran yang mendukung revolusi pembelajaran 4.0, sehingga siswa memiliki minat dan motivasi yang kuat untuk belajar. Guru yang mengajar pasti memilki bank soal. Sehingga aplikasi ini dapat digunakan sebagai sarana menyimpan soal dan untuk kemudian dianalisis soal tersebut sehingga mampu menjadi soal yang valid, reliabel dan memiliki daya beda serta tingkat kesukaran yang baik. Sehingga pembelajaran menjadi lebih menyenangkan (Lasia Agustina, Sesiomadika 2019 Hal 1-7) 
Leony Sanga L. P. dalam JDP yang berjudul Peningkatan Konsentrasi Belajar Mahasiswa (Purba L. S., 2019). Melalui Pemanfaatan Evaluasi Pembelajaran Quizizz pada mata kuliah Kimia Fisika I menyimpulkan bahwa terjadi peningkatan pada konsentrasi belajar mahasiswa melalui pemanfaatan evaluasi pembelajaran quizizz pada kuliah Kimia Fisika I sebesar 0,45 dengan interpretasi peningkatan sedang. Indikator ketelitian mengalami peningkatan 0,53 dan indikator pemahaman mengalami peningkatan paling rendah 0,36. Sehingga evaluasi pembelajaran dengan menggunakan Quizizz membantu meningkatkan konsentrasi belajar mahasiswa.

Penelitian Lasia agustina tahun 2019 dan leony sanga L.P tahun 2019 selajan dengan penelitian kami, yaitu pembelajaran menggunakan Quizizz. Yang membedakan "Pembelajaran matematika melalui media game Quizizz untuk meningkatkan hasil belajar matematika tingkat SMP". Berdasarkan latar belakang di atas, masalah penelitian difokuskan kepada bagaimana menjadikan aplikasi Quizizz sebagai media pembelajaran matematika yang menyenangkan dan meningkatkan hasil belajar, sehingga peserta didik atau siswa di kelas dapat belajar dimanapun, kapanpun, dan dengan cara apapun tanpa terhalang tembok atau dinding-dinding kelas.

\section{METODE PENELITIAN}

Penelitian ini adalah Penelitian Tindakan Kelas (PTK) yang dilaksanakan untuk mengetahui hasil belajar, keterampilan proses siswa, yang mengimplementasikan game Quizizz. Penelitian ini menggunakan model Kemmis dan Mac Tanggart (Kemmis, 1992) dengan empat tahapan yaitu perencanaan, pelaksanaan tindakan, observasi atau pengamatan, dan refleksi. Penelitian ini dilaksanakan di SMPN 2 Bojonegara pada semester II tahun pelajaran 2019/2020 bulan Januari - Februari 2020. Subjek penelitian ini adalah siswa kelas VIIIA yang berjumlah 28 siswa yang terdiri dari 15 siswa laki - laki dan 13 siswa perempuan. Penelitian ini dirancang dalam 2 siklus yang setiap siklusnya terdiri dari empat tahapan yaitu : 1) perencanaan; 2) pelaksanaan tindakan; 3) observasi atau pengamatan; 4) refleksi. Setiap siklus terdiri dari dua pertemuan tatap muka. Setiap siklus dilaksanakan sesuai dengan perubahan yang ingin dicapai seperti apa yang telah didesain. Teknik pengumpulan data dalam penelitian ini yaitu : a) Tes, digunakan untuk memperoleh tes data hasil belajar siswa. Data tes ini diambil pada setiap siklus yang terdiri dari dua siklus, sehingga tiap siklus diperoleh data post test mengenai materi teorema Phytagoras; b) Observasi, digunakan untuk memperoleh data mengenai keterampilan proses siswa dalam proses pembelajaran yang mengimplementasikan media game Quizizz.

\section{HASIL DAN PEMBAHASAN}

Penelitian ini dirancang dalam 2 siklus, yang setiap siklusnya terdiri dari 4 tahapan, yaitu: 1) Perencanaan (Planning), 2) Pelaksanaan (Action), 3) Observasi atau Pengamatan (Observation), 4) Refleksi (Reflecting). Setiap siklus terdiri dari 2 pertemuan tatap muka dan dilaksanakan sesuai dengan perubahan yang ingin dicapai, seperti apa yang telah didesain. Berikut tahapan yang dilakukan pada setiap siklus dalam penelitian ini: 


\section{Siklus 1}

\section{Perencanaan}

Tahapan ini terdapat beberapa langkah : a) Menentukan tujuan atau kompetensi yang hendak dicapai; b) Menyiapkan media pembelajaran Game Quizizz; c) Menentukan tahapan proses pembelajaran dengan menggunakan Game Edukasi Quizizz; d) Merancang seluruh perangkat pembelajaran dari siklus I hingga siklus II; e) Membuat instrumen penelitian soal test, lembar pengamatan keterampilan proses yang digunakan dari siklus I hingga siklus II; f) Diskusi dengan teman sejawat untuk pelaksanaan observasi pada saat proses penelitian di kelas.

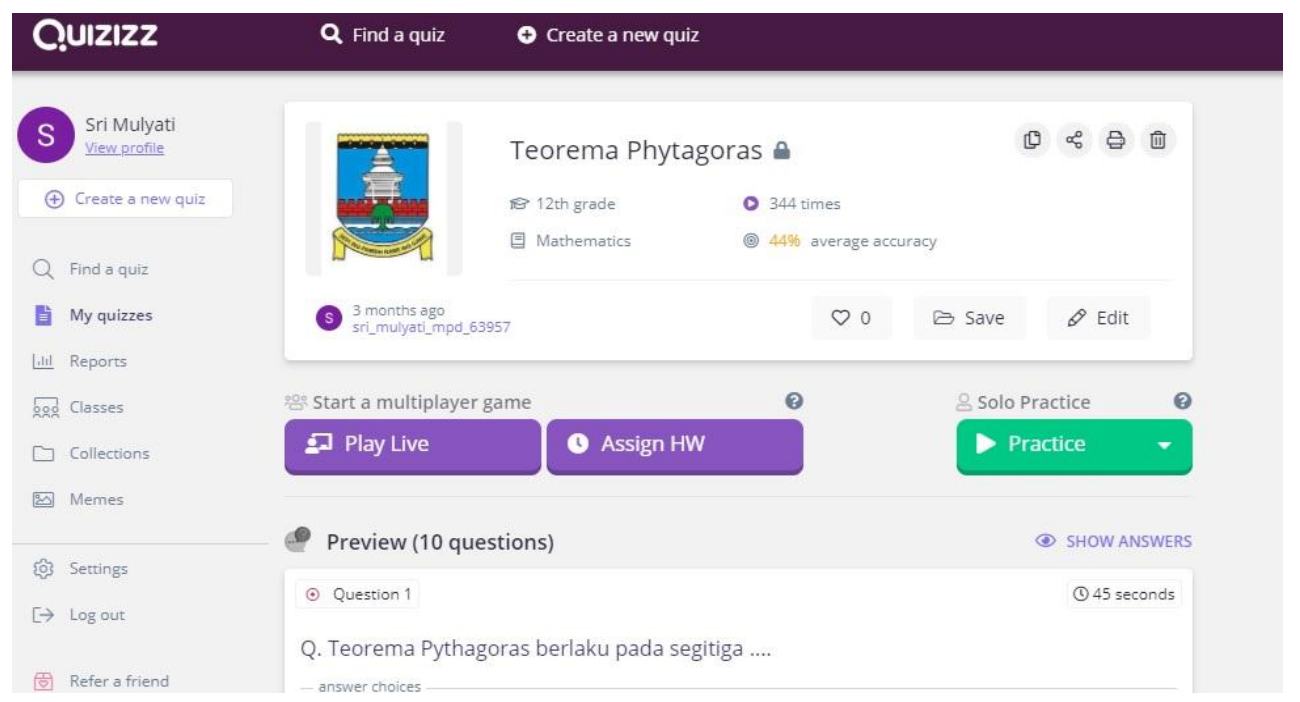

Gambar 1. Perencanaan Game Quizizz

\section{Pelaksanaan}

Pelaksanaan Tahap ini merupakan tahap pelaksanaan penggunaan Game Quizizz yang terdiri dari 2 pertemuan, dimana pertemuan pertama merupakan pre test dilanjutkan dengan pembelajaran. Pada proses pembelajaran diawali dengan penyampaian kompetensi dasar dan indikator serta tujuan pembelajaran dan materi Teorema Phytagoras. Guru menyampaikan cara penggunaan Game Quizizz kepada siswa. Selanjutnya guru meminta siswa untuk menyelesaikan beberapa soal yang berada di Game Quizizz. 


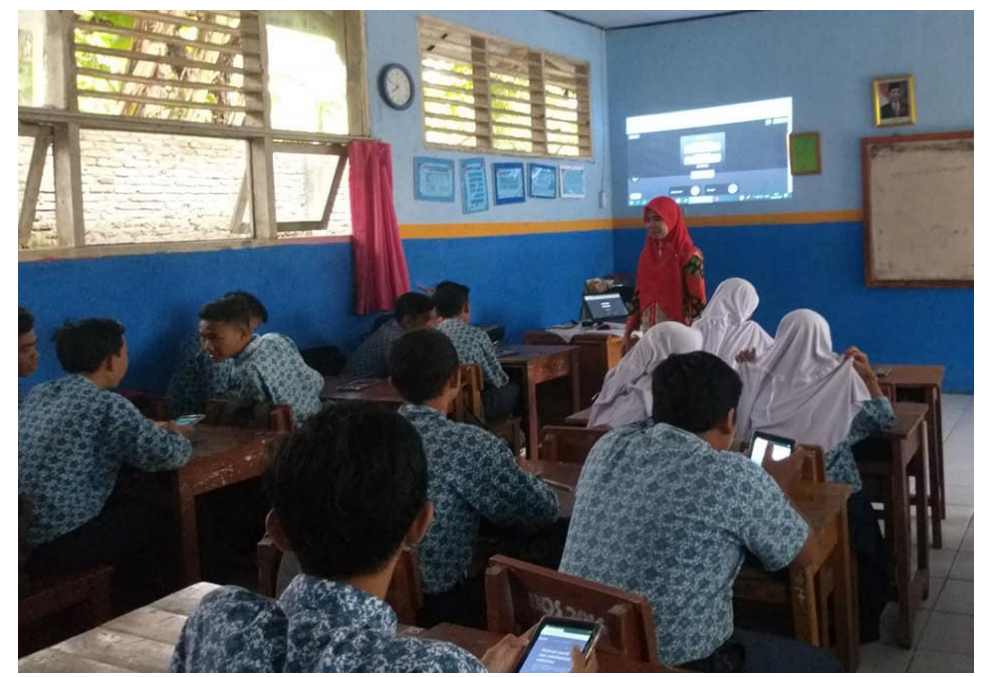

Gambar 2. Pelaksanaan Game Quiziz

3. Observasi atau Pengamatan

Observasi atau Pengamatan Pada tahap ini dilakukan untuk memperoleh data mengenai keterampilan proses siswa dalam proses pembelajaran yang menggunakan Game Quizizz.

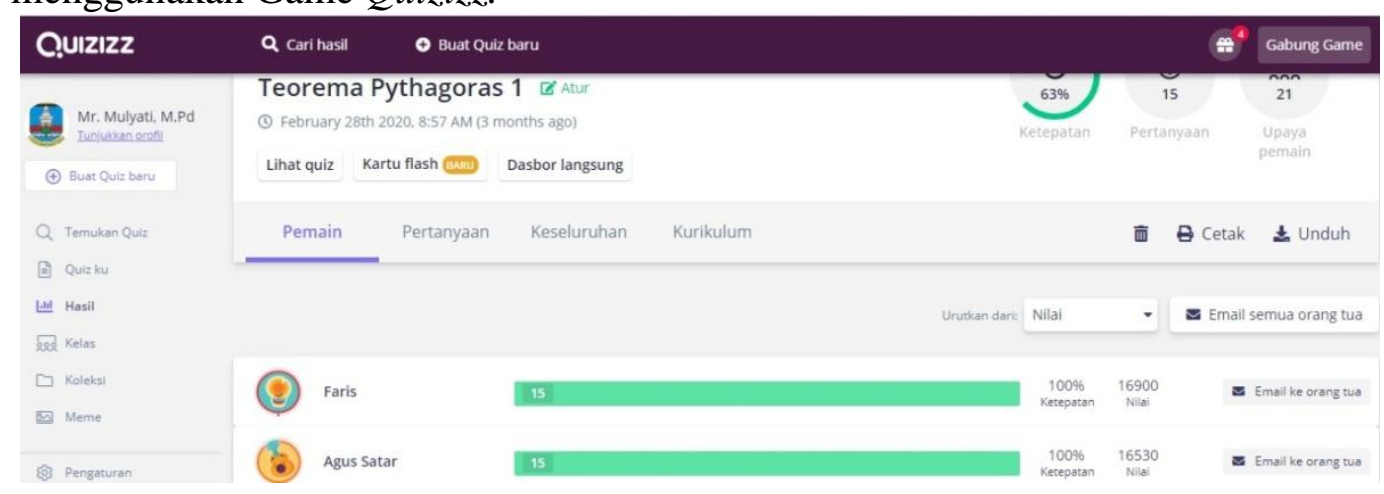

Gambar 3. Keterampilan Proses

\section{Refleksi}

Refleksi Mendiskusikan hasil pelaksanaan pembelajaran dan pengamatan atas tindakan pada pelaksanaan siklus I dengan rata rata nilai $63 \%$, untuk dilakukan perbaikan-perbaikan dalam pelaksanaan pembelajaran pada siklus II.

\section{Siklus II}

\section{Perencanaan}

Tahapan siklus II ini terdapat beberapa langkah : a) Menentukan tujuan atau kompetensi yang hendak dicapai; b) Menyiapkan media pembelajaran Game Quizizz; c) Menentukan tahapan proses pembelajaran dengan menggunakan Game Edukasi Quizizz yang sama pada siklus I d) Merancang seluruh perangkat pembelajaran dari siklus II e) Membuat instrumen penelitian soal test, lembar pengamatan keterampilan proses yang digunakan dari siklus I 


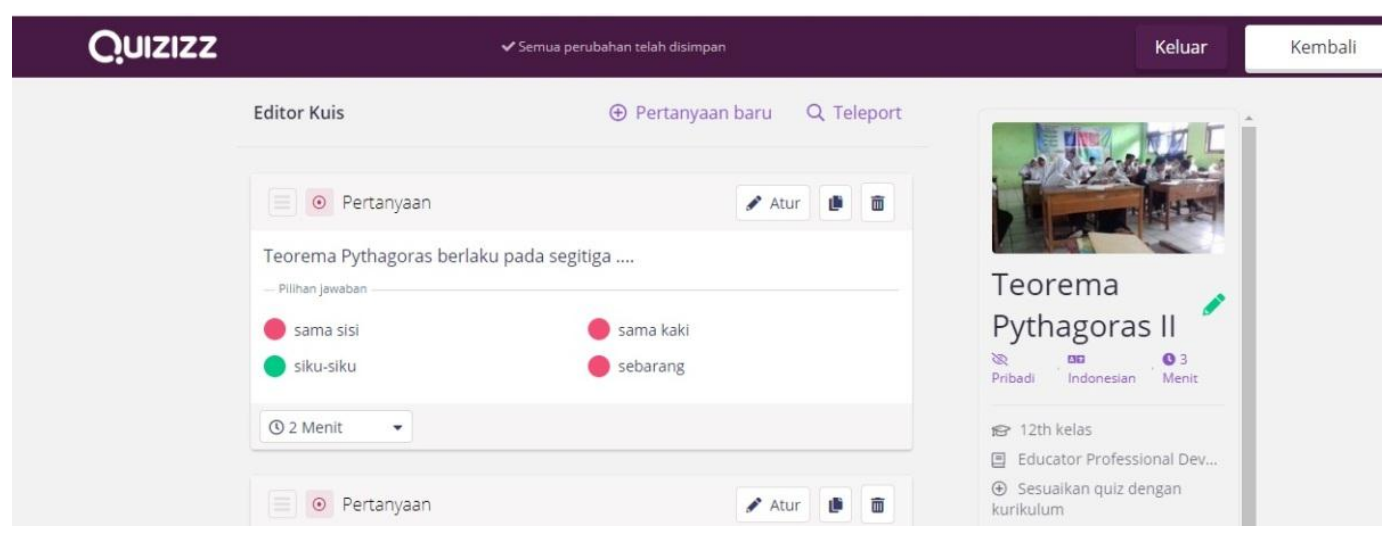

Gambar 4. Quizizz ke II

\section{Pelaksanaan}

Pelaksanaan Tahap siklus II ini merupakan tahap pelaksanaan penggunaan Game Quizizz yang terdiri dari 2 pertemuan, dimana pertemuan pertama merupakan pre test dilanjutkan dengan pembelajaran. Pada proses pembelajaran diawali dengan penyampaian kompetensi dasar dan indikator serta tujuan pembelajaran dan materi Teorema Phytagoras. Guru langsung menyuruh mengerjakan Game Quizizz kepada siswa. Selanjutnya guru meminta siswa untuk menyelesaikan beberapa soal yang berada di Game Quizizz.

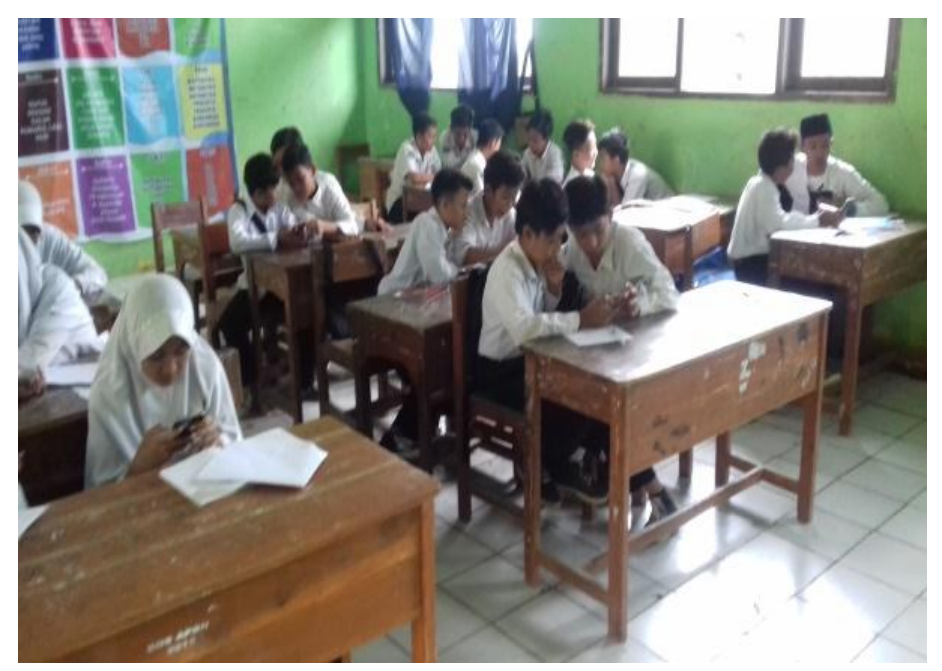

Gambar 5. Suasana pelaksanaan Q2

\section{Pengamatan}

Pengamatan Pada tahap siklus II ini dilakukan untuk memperoleh data mengenai keterampilan proses siswa dalam proses pembelajaran yang menggunakan Game Quizizz mengalami peningkatan dengan rata-rata 78\%. 


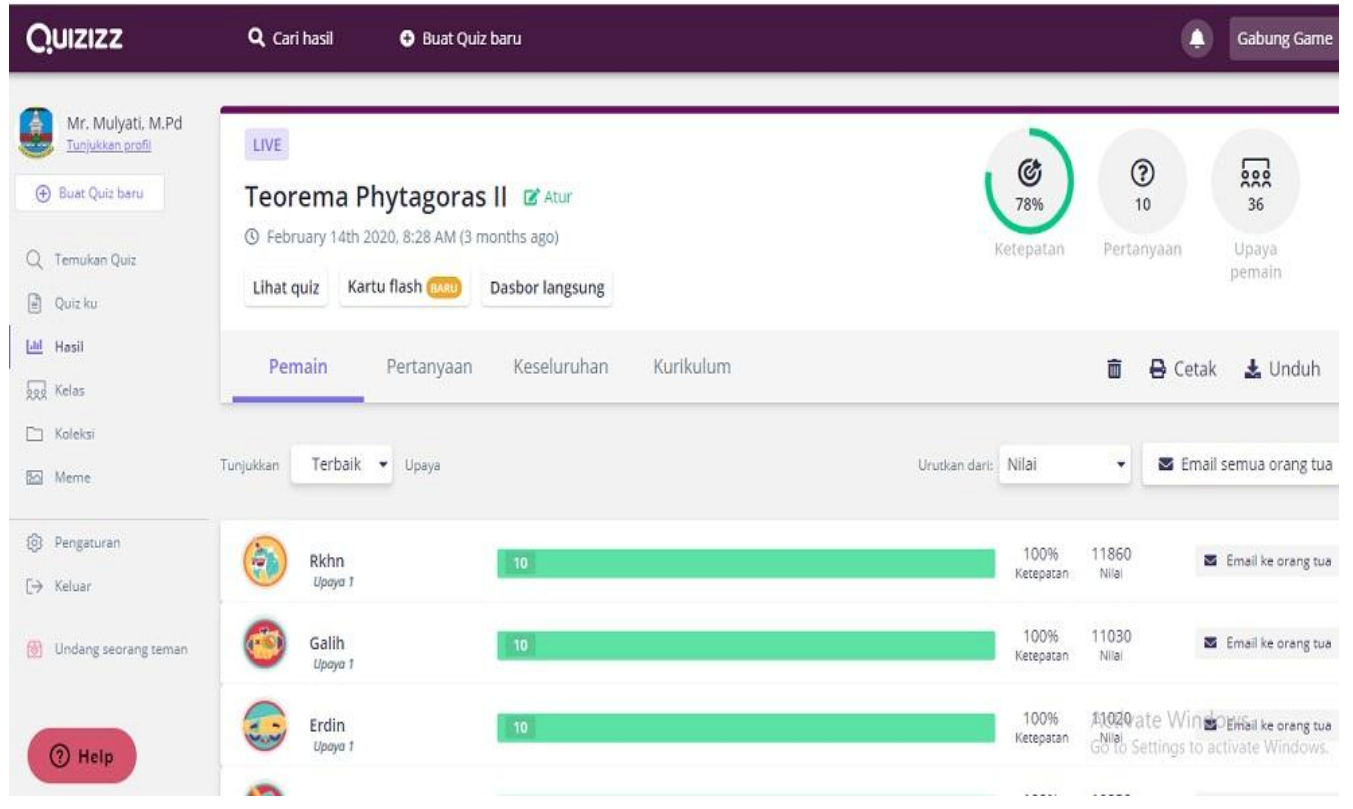

Gambar 6. Hasil Quizizz ke II

\section{Refleksi}

Berdasarkan hasil Siklus II keterampilan proses siswa dalam proses pembelajaran yang mengimplementasikan Game Quizizz untuk menyelesaikan soal - soal terkait materi Teorema Phytagoras didapat hasil berikut ini, Pada siklus I diperoleh rata - rata keterampilan proses sebesar 67 sedangkan siklus II diperoleh rata - rata 78, sehingga mengalami kenaikan $11 \%$.

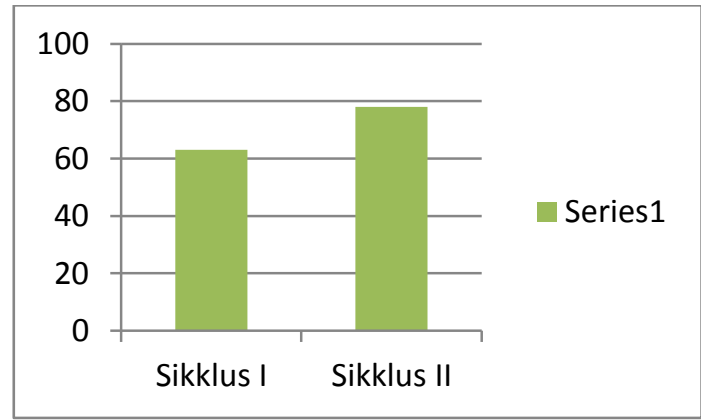

Gambar 7. Hasil Belajar Quizizz

Berdasarkan hasil pada diagram diatas dapat dilihat bahwa terdapat peningkatan pada tiap siklusnya antara test hasil belajar pada materi Teorema Phytagoras. Hal ini ditunjukkan dengan adanya peningkatan rata - rata post test hasil belajar antara siklus I dan siklus II. Pada siklus I diperoleh rata - rata hasil belajar sebesar 63 sedangkan pada siklus II diperoleh rata - rata hasil belajar sebesar 78 karena di siklus II jauh lebih siap baik Perencanaan, Pelaksanaan, Pengamatan dan Refleksi.

Pembelajaran menggunakan Quizizz merupakan salah satu metode pembelajaran berbasis internet yang memungkinkan diketahui tingkat penguasaan 
masing-masing materi dan masing-masing peserta secara online dan dapat disimpan dalam aplikasi, Kekurangan pembelajaran menggunakan Quizizz adalah tergantung jaringan internet di tempat pembelajan. Berdasarkan hasil penelitian ini terdapat banyak manfaat dan kelebihan pembelajaran menggunakan aplikasi Quizizz sehingga perlu dikembangkan lagi baik pelajaran matematika maupun bidang studi yang lain.

\section{SIMPULAN DAN SARAN}

Kuis online Quizizz dapat digunakan oleh Guru mata pelajaran matematika Khususnya dan mapel lain umumnya, untuk melihat sejauh mana siswa dalam belajar teorema Phytagoras. Penggunaan yang mudah dan hasil yang cepat dalam proses penilaiannya menjadikan aplikasi ini layak digunakan sebagai aplikasi pembelajaran. Terdapat peningkatan hasil belajar siswa dari siklus I sebesar 63 dan siklus II sebesar 78 dan Peningkatan kemampuan pendidik dalam memanfaatkan media ini sangat diperlukan karena masih kurangnya pengetahuan dan ketrampilan pendidik terhadap Quizizz untuk membuat dan memanfaatkan media pembelajaran. Kekurangan pembelajaran menggunakan Quizizz adalah bergantung pada jaringan internet.

Media pembelajaran berupa Quizizz dapat dimanfaatkan oleh pendidik sebagai sebagai salah satu alternatif media pembelajaran berbasis TIK untuk dimanfaatkan semaksimal mungkin guna mencapai tujuan pembelajaran. Pemanfaatan media pembelajaran jenis ini dapat mengatasi adanya kekurangan pemanfaatan media pembelajaran sejenis untuk mendukung pencapaian tujuan pembelajaran. Pemanfaatan media pembelajaran ini dapat mengatasi berbagai permasalahan yang dihadapi dalam proses pembelajaran dan diperlukan tindak lanjut dengan perancangan pengembangannya untuk proses pembelajaran selanjutnya.

\section{DAFTAR RUJUKAN}

Agustina, L. (2019). PEMBELAJARAN MATEMATIKA MENYENANGKAN DENGAN APLIKASI KUIS ONLINE QUIZIZZ . Sesiomadika (Hal 1-7).

Awal, N. M. (2016). Pengaruh Perhatian Orang Tua, Konsep Diri, Persepsi Tentang Penjas Terhadap Hasil Belajar Penjas Melalui Motivasi Belajar Siswa Kelas VIII SMP Negeri di Kecamatan Ujung Loe Kabupaten Bulukumba. Penjas dan Pembelajarannya 4(2): 64-79.

Dimyati, M. d. (2015). Belajar dan Pembelajaran. Jakarta: Rineka Cipta. Dina.Gasong. (2018). Belajar dan pembelajaran. Yogyakarta: Deepublish. Henry, S. (2010). Cerdas dengan Game. Jakarta: PT Gramedia Pustaka Utama .

Herlambang, A. \&. (2016). Edmodo untuk Meningkatkan Kualitas Perencanaan Proyek dan Efektivitas Pembelajaran di Lingkungan Pembelajaran yang Bersifat Asinkron. Jurnal Teknologi Informasi dan Ilmu Komputer (JTIIK), $3(2), 1-8$.

Kemmis, S. \&. (1992). The Action Research Planner. Australia.

Maghfiroh, N. W. (2018). Pengaruh Penerapan Media Edmodo Terhadap Hasil Belajar Pendidikan Agama Islam di SMK Anwarul Maliki Sukorejo Pasuruan. Al Ghazwah, 2(2), 207-226. 
Mei, Y. S. (2018). Implementing Quizizz as Game Based Learning in the Arabic Classroom. European Journal of Social Sciences Education and Research. 12(1): 211.

Nasrullah, E. \&. (2017). Efektivitas Penggunaan Media Edmodo pada Pembelajaran Matematika Ekonomi Terhadap Komunukasi Matematis. SYMMETRY: Pasundan Journal of Research on Mathematics Learning and Education, 2(1), 1-10.

Purba, L. S. (2019). Peningkatan Konsentrasi Belajar Mahasiswa Melalui Pemanfaatan Evaluasi Pembelajaran Quizizz Pada Mata Kuliah Kimia Fisika I. JDP. 12(1) : 29

Rusman. (2017). Belajar dan Pembelajaran Berorientasi Standar Proses Pendidikan. Jakarta: Kencana 